\title{
AS FLORES DE JOSEFA: LINHA DE JOALHARIA DE AUTOR THE JOSEFA'S FLOWERS: A LINE OF AUTHOR'S JEWELRY
}

Mónica Romãozinho* Instituto Politécnico de Castelo Branco

CIAUD

\section{Resumo}

O Barroco Jesuítico em Portugal espelha um momento de afirmação da nacionalidade mas é também reflexo de um contexto internacional, marcado pela Contra Reforma e pela necessidade de inebriar através de imagens, correspondendo a pintura a um instrumento privilegiado de comunicação. $\mathrm{O}$ presente artigo incide no processo criativo subjacente a uma linha de joalharia que tem como conceito a natureza vista através do olhar de Josefa de Óbidos, importante pintora que marca o século XVII. Aborda-se a génese do projecto que reside na interpretação de variantes como o sentido poético de metamorfose e de passageiro, assim como o sentido de espacialidade presente nos elementos retratados pela artista, marcados por contrastes intensos de claro-escuro e assimetria na sua contextualização. Na metodologia projectual, cruzam-se esquissos, modelação tridimensional e impressão 3D, que nos permitiram testar a versatilidade das peças, constituídas por elementos modulares essencialmente dinâmicos, que o público pode girar, suscitando diferentes leituras.

Palavras-chave: Design, Espacialidade, Joalharia, Josefa de Óbidos, Natureza.

Abstract

The Baroque Jesuit in Portugal reflects a moment of affirmation of nationality but also reflects an international context marked by the Counter Reformation and the need to inebriate through images, considering painting as a privileged instrument of communication. This article focuses on the underlying creative process to a jewelry line that has the concept of the nature seen through the eyes of Josefa de Obidos, important painter that marks the seventeenth century. We begin with an approach to the project genesis that lies in the interpretation of variants as the poetic sense of metamorphosis and passenger, as well as the sense of this spatiality present in the elements depicted by the artist, marked by strong contrasts of light and dark and asymmetry in its context. The

\footnotetext{
*E-mail: monica.romaoz@gmail.com
} 
project methodology lies in the intersection of sketches, three-dimensional modeling and 3D print, which allowed us to test the versatility of the pieces, consisting essentially of modular elements, which the public can turn, raising different readings.

Keywords: Design, Jewellery, Josefa de Óbidos, Nature, Spatiality.

\section{O conceito e o sentido do passado para o Design contemporâneo}

O presente artigo foca a criação de uma linha de joalharia a partir da leitura e reinterpretação das naturezas-mortas de Josefa de Óbidos (1630-1684), numa perspectiva conceptual e metodológica.

Justifiquemos a escolha da obra pictórica de Josefa de Ayala e Cabrera, nascida em Sevilha, mais especificamente das naturezas-mortas, como conceito ou filosofia de base do projecto de uma linha de joalharia de autor. Em primeiro lugar, a sua obra destaca-se pela qualidade e extensão demonstrando que a pintora estava a par das experimentações desenroladas no contexto internacional. Foi altamente influenciada pelo seu pai e mestre, Baltazar Gomes Figueira (1604-1674) que fez a sua formação em Sevilha. Foi também "apadrinhada por um importante pintor espanhol da época, Francisco Herrera, e começou por copiar os modelos que encontrava na oficina do pai, alguns de Francisco de Zurbarán, que ele terá chegado a conhecer"1. Estas referências terão permitido que Josefa evoluísse no seu trabalho apesar deste mesmo se desenrolar num ambiente provinciano, em Óbidos. A sua religiosidade, espiritualidade, mas também um forte perfeccionismo, seriam reflexo de um Barroco que se afirma com a restauração da independência (1640). Por outro lado, trata-se de uma mulher que se emancipa fazendo da pintura a sua profissão. Trata-se de algo inédito no campo das artes em Portugal até ao século XIX e viragem para o século seguinte, em que assistimos à eclosão de artistas como Aurélia de Sousa (18661922), Sarah Affonso (1899-1983) ou Vieira da Silva (1908-1922).

Interessa-nos, num segundo momento, reflectir sobre o facto de, neste e em outros projectos, considerarmos a História do Design como parte integrante da nossa metodologia projectual. Qual a operatividade de obras como esta para o presente e mais especificamente para os designers que, como nós, projectam no contexto económico e social contemporâneo? Victor Margolin (1941), professor de História do Design na Universidade de Illinois, procurou precisamente responder a esta dúvida: "What answers might we find in the past to questions about the present when the current configuration of actions and events seems so volatile and unstable?"2 Também John A.Walker (1938), crítico de arte e historiador, afirmaria que

"the first responsibility of design historians is, therefore, to reconstruct the meanings and significances which designed goods had 
for those for whom they are made. However, their task does not end there because it is also important to trace their subsequent history and consider what meanings, if any, they have for people now"3.

Parece-nos fundamental enfatizar a importância destes significados para quem investiga no campo da História do Design mas também para que projecta, não numa perspectiva de incentivar revivalismos resultantes de modas cíclicas, mas pela possibilidade de inscrevermos cada projecto num quadro de relações de continuidade e compreender o comportamento social e imaginário colectivo do próprio público a que este se destina:

"O conhecimento acerca do passado pode servir, deste modo, como crítica das condições presentes; pode fazer com que o presente pareça menos imutável. (...) Na realidade, o presente é parte de um processo histórico em curso; na verdade o presente é o culminar de um processo histórico"4.

Nesta perspectiva, Margolin refere Eric Hobsbawm (1917), historiador, que defende a importância da formalização de um passado social, na medida em que reconhecer as várias componentes da sociedade e os seus diferentes graus de mudança pode contribuir para um processo equilibrado de transformação social que não conduza a uma instabilidade social ou colapso ${ }^{5}$.

\section{Sobre o Barroco enquanto pano de fundo da obra pictórica de Josefa de Óbidos}

Josefa de Óbidos destacou-se no período barroco em Portugal associado a uma afirmação da nacionalidade, corrente que durante tanto tempo foi desvalorizada face ao manuelino, intimamente associado aos Descobrimentos. O início do século XVII havia sido marcado pela obra de André Reinoso (c.15901641) que aprendeu os princípios de composição do maneirismo italiano durante a sua formação na oficina de Simão Rodrigues, acabando por evoluir para uma obra mais naturalista e marcada pelo domínio da técnica de contraste claro-escuro de Caravaggio $^{6}$. A ele sucederam tanto Josefa de Óbidos (1630-84) como Bento Coelho (1648-1708?), seu contemporâneo, que reintroduziram na pintura uma paleta cromática rica pela sua diversidade, embora a obra de Josefa revele um maior perfeccionismo e uma execução mais lenta ${ }^{7}$. Recorreria a estampas e gravuras como referências paralelas à literatura religiosa, tão determinante para as suas temáticas: as naturezas-mortas, o cordeiro de Deus, o menino Jesus Salvador do Mundo. Destacam-se também as duas versões do casamento místico de Santa Catarina, um dos temas recomendados pelos reformistas católicos ${ }^{8}$. Tratam-se de trabalhos que espelham uma representação detalhada de interiores, mobiliário e elementos como tapeçarias e panejamentos (1647) que testemunham a importância dos têxteis coloridos e orientais para cobrir 
pavimentos, plataformas, mesas e arcas ${ }^{9}$. Por sua vez, as naturezas mortas são reveladores dos hábitos alimentares da época e do modo como eram servidos, de que é exemplo a presença frequente de púcaros de barro que surgem em posição invertida quando não eram utilizados e sempre associados às doçarias pois estas faziam-se acompanhar de água servida nos mesmos ${ }^{10}$.

Mesmo em pleno século XIX, autores como Garret, Herculano ou Oliveira Martins e Antero olharão para o Barroco como uma arte decadente e associada a "protagonistas maléficos responsáveis por todos os males da pátria, como os Braganças, os Jesuítas e a Inquisição"11. Esta atitude faz-se sentir durante o Estado Novo, sendo o manuelino reconhecido como estilo genuinamente nacional. $\mathrm{Na}$ verdade, o Barroco foi mais longe do que ideias pré-concebidas e uma sucessão de adjectivos: "A explicação da produção artística de qualquer época tem de fazerse à luz da cultura artística (dos artistas e dos encomendadores) então dominante e que é revelada pelos textos teóricos"12.

Não só a restauração de independência em Portugal e respectivas guerras constituiriam o cenário de fundo, mas ainda o Concílio de Trento e a ContraReforma, (1640-1668). No Barroco, quer a pintura quer a escultura apresentam uma forte carga simbólica, funcionando como uma linguagem eficaz junto aos que não sabiam ler extremamente importante para a Igreja para a qual trabalhavam artistas e escritores ${ }^{13}$. Captava-se o público a partir de temas ou encenações cuja contemplação pode despertar sentimentos religiosos ou políticos ${ }^{14}$. Se os retratos dão resposta à necessidade de uma iconografia que afirme a nova dinastia de Bragança ${ }^{15}$, as naturezas-mortas serão também um veículo religioso. A visão directa das coisas, a sua aparência, é fundamental para a sociedade no Barroco pois estas as representações simbólicas tinham uma força reforçada pela repetição dos temas representados que podem suscitar atitudes de adesão, entrega ${ }^{16}$.

No âmbito da iconografia da Contra-Reforma, destaca-se o valor das naturezas-mortas, que reforçava a leitura das plantas e animais como imagens religiosas, ou seja, como forma de aproximação ao divino pois enquanto os protestantes procuravam afastar as imagens e o ornamento, os católicos reforçavam a utilização de flores como conceito de simbologia e moralização católica ${ }^{17}$. Em 1750, o teólogo Molanus produziu inclusivamente um tratado sobre iconografia cristã no qual insistia no papel da pintura ${ }^{18}$. Para além do interesse da Igreja em defender a sua ideologia, podem ser apontados outros factores: novo olhar sobre a natureza em parte despertado pelas expedições científicas (também a introdução de novas espécies associada à exploração de novas terras longínquas), o estudo sistemático da História natural espelhado na ilustração científica - descrição e representação rigorosas das espécies vegetais e animais, criação de vários jardins botânicos e Gabinetes de História Natural ${ }^{19}$.

A natureza-morta surge na Europa no final do século XVI, sendo o século seguinte considerado como idade de ouro desta tipologia: Holanda, Flandres e França, assim como Itália e Espanha, sendo conhecida neste último caso como bodegón, género criado por Sánchez Cotán (1560-1627) ${ }^{20}$. Recorria-se a uma linguagem simbólica, através do recurso a elementos como a flora e fauna que 
simbolizam o poder divino, os atributos da Virgem Maria, a castidade e virgindade ou o sofrimento da paixão de Cristo e Ressurreição, a fertilidade e felicidade mas também o pecado. Alguns símbolos desvelavam até uma certa dicotomia como o pepino que pode simbolizar o pecado mas também o atributo da Virgem porque viveu rodeada pelo pecado sem ser atingida ${ }^{21}$. Como concluiu a autora Sónia Azambuja, na parábola bíblica, as plantas são portadoras de uma mensagem moralizante, em que é feita uma analogia entre a árvore e o homem:22

"Não há árvore boa que dê mau frutos, nem árvore má que dê bom fruto. Cada árvore se conhece pelo seu fruto; não se colhem figos dos espinhos, nem uvas dos abrolhos. O homem bom, do bom tesouro do seu coração tira o que é bom; e o mau, do mau tesouro tira o que é mau; pois a boca fala da abundância do coração. ${ }^{23}$ Conclui, de seguida, que a "leitura" do simbolismo das plantas pode auxiliar a desvendar o significado da obra de arte determinando um novo "olhar" para a arte" 24 .

A pintura era, portanto, um veículo determinante de disseminação da fé cristã mas ao mesmo tempo um campo de criação para o artista que não se via mais submetido à arquitectura, como evidencia Jose Maravall (1911-1986), assumindo um predomínio face às outras artes. Tal não acontecera no Renascimento, período marcado pelo contributo de Sebastiano Serlio (1475c.1554) que encarava a pintura como mais uma parte da obra de arquitectura enquanto todo dotado de unidade, devendo o arquitecto considerar no seu projecto não só os ornamentos em pedra mas a pintura "de pincel" destinada a paredes ou partes destas, recomendando um estudo criterioso da cor equacionada numa perspectiva de harmonia com as restantes componentes ${ }^{25}$.

Um dos aspectos mais fascinantes deste período é então a atenção muito particular dada ao campo pictórico pelo homem barroco em detrimento de outras áreas criativas: "no es por la capacidad imitativa del natural que com el empleo de los pinceles se pueda adquirir, sino por su facultad de reformar e rehacer lo dado por la naturaleza, que com el manejo de aquéllos el artista alcanza". ${ }^{26} \mathrm{O}$ mesmo autor, Maravall, conclui que a arte não pode ser entendida como uma cópia, porque para além de ser impossível, a intervenção do artista tem sempre um carácter activo, introduz um elemento novo, transforma o objecto para permitir a sua entrada no mundo da arte: "la pintura se define como uma función poética, en el sentido epistemológico de la palabra, esto es, creadora"27.As natureza-mortas de Josefa de Óbidos (Fig.1) enquadram-se neste contexto internacional barroco, partilhando premissas não só com os espanhóis como os holandeses e franceses.

A colecção apresentada neste artigo parte deste mesmo pressuposto de reinvenção do objecto observado, neste caso, da obra de Josefa de Óbidos, tendo como objectivo criar peças enquadráveis no universo da moda e, que à semelhança de um coordenado, expressem a personalidade, que dialoguem com a 
sociedade, ecoando as preferências de quem a veste, revelando a sua sensibilidade e maneira de pensar ${ }^{28}$.

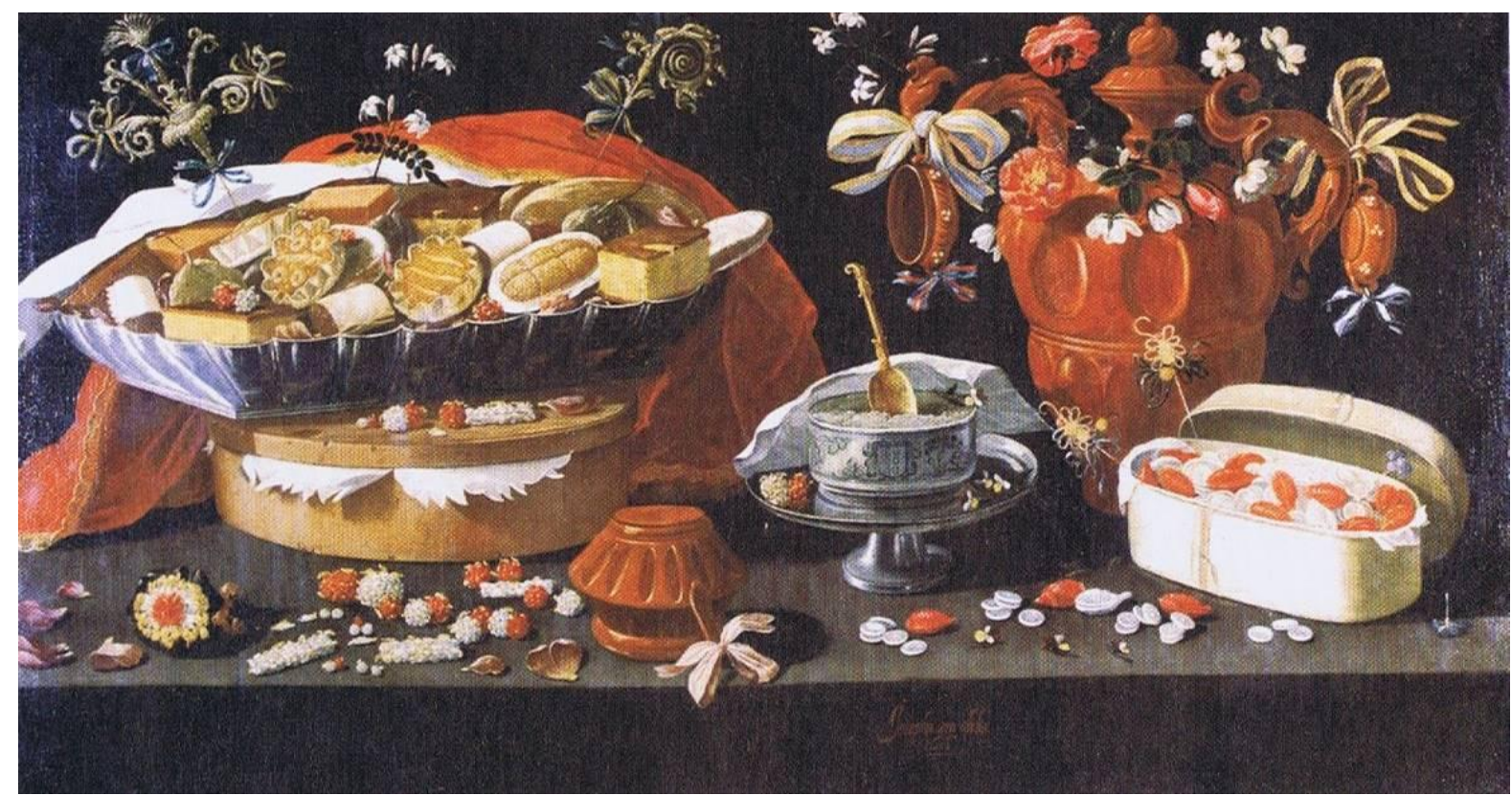

Fig. 1. Natureza-morta: caixas, barros e flores. Josefa de Óbidos. Biblioteca-Museu A.Braancamp Freire, Santarém. História da Arte Portuguesa, Barcelona, Círculo dos Leitores, 1995, p.18.

\section{A natureza e a espacialidade}

A pintura do Barroco é uma pintura do inacabado, do variável, do instável, que capta o homem e a vida ${ }^{29}$, apoiando-se este sentido de mutação na própria natureza. A consciência do passageiro, do efémero, da metamorfose a que tudo se submete espelha-se no modo como a flora se dispõe nos quadros da artista, umas vezes mais estática, outras desfragmentando-se em movimento radial sobre o plano do pavimento ou de uma mesa ou bufete, reforçando o sentido de profundidade da cena. As flores estão presentes não só nesta temática pictórica mas também nos retratos, com um fundo envolvente que enfatiza as qualidades do retratado.

Nas naturezas mortas de Josefa de Óbidos, é constante a presença da rosabrava, símbolo da alma fiel, castidade e da Igreja. Ao nível da concepção da linha de joalharia, procedemos à decomposição das superfícies que compõem os volumes das pétalas de uma rosa, como se estes se desestruturassem sobre um plano, mas atrás deste aparente caos, esconde-se uma ordem no sentido em que existem traçados reguladores iniciais assim como uma lógica modular. Procurámos alcançar o sentido de aparente mutabilidade e também de inacabado através do volume das pétalas que nasce do jogo de claro-escuro de relevos e reentrâncias e que, a certa altura, dá lugar a uma estrutura despojada de enchimento que nos sugere o efémero. A oposição claro-escuro decorre da da percepção dos trabalhos de Josefa de Óbidos e de outros da época pois a pintura foi mais afirmativa a este nível, ao contrário da arquitectura que, em Portugal, não revela jogos intensos de 
claro-escuro e enfâse de elementos salientes como pilastras, cariátides, molduras ou sancas. O colar seria moldado ao nível da curvatura através de ar quente, adaptando-se deste modo ao corpo (Fig.2). Se a pregadeira, dada a sua escala, é pensada como uma peça mais plana, no caso do colar procedemos à criação de movimentos ondulatórios de modo a adaptar-se ergonomicamente ao corpo.

Apesar da simetria e a axialidade constituírem estratégias presentes na arquitectura barroca religiosa em Portugal, este princípio de composição é alheio à pintura que reinterpreta uma realidade mutável, composta por assimetrias e pelo sentido de diversidade.

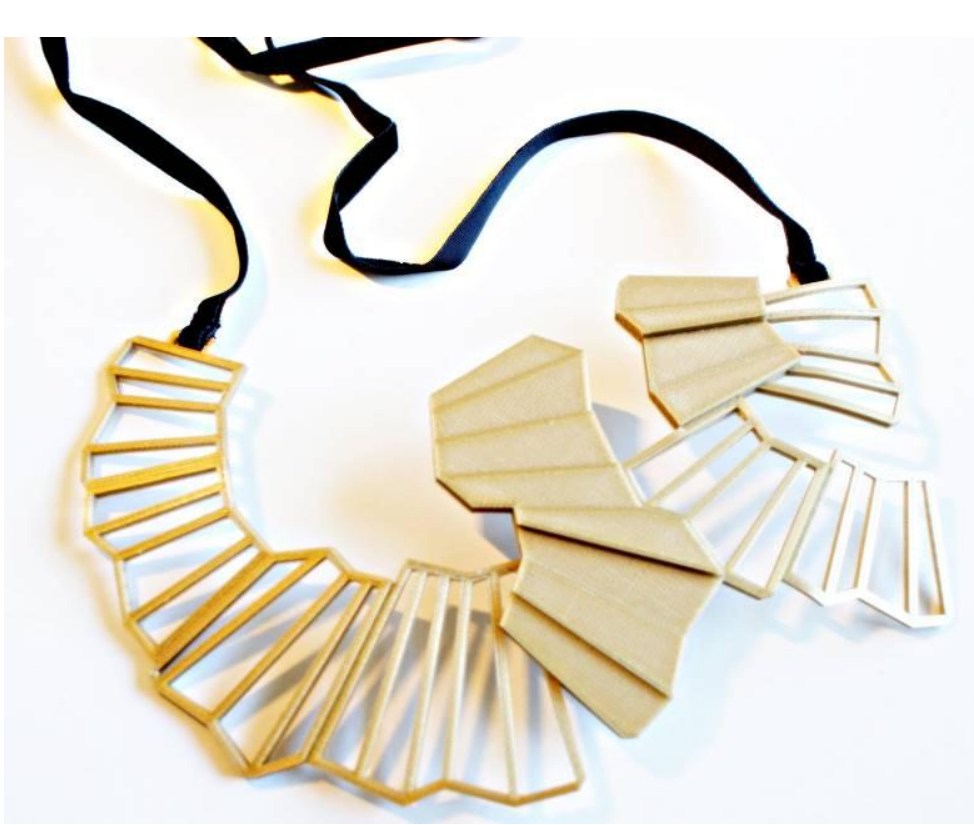

Fig. 2. Colar da colecção As flores de Josefa. 2015. Foto: Mónica Romãozinho.

Por outro lado, é também um princípio alheio à própria natureza. A composição das peças de joalharia desdobra-se, portanto, em elementos modulares assimétricos (Fig.3), tal como acontece com as estruturas contínuas da natureza retratadas por Josefa nas suas diferentes fases, de carácter evolutivo, embora os elementos na natureza não sejam sempre iguais pois o ambiente condiciona a sua forma e cor, como acontece com uma árvore por exemplo:

"Teoricamente, todas as folhas de uma mesma árvore deveriam ser iguais, idênticas, mas isso só aconteceria se pudessem crescer num ambiente privado de influências e de variações. Todas as laranjas deveriam ser esferas semelhantes, mas uma cresce ao sol, outra à sombra, outra entre dois ramos muito juntos, e por isso são todas diferentes" 30 . 
Segundo este princípio observável na natureza a transposto para este projecto, pétalas, opacas ou lineares, deslocam-se umas em relação às outras, como se um conjunto de tensões as fizesse deslizar no plano horizontal ou vertical ou ainda rodá-las criando sobreposições.

No caso dos anéis (Fig.4), mantém-se este discurso mas o corpo superior seria condicionado pela abertura onde encaixa o aro, pois a prototipagem melhora consideravelmente com a impressão das peças deitadas, contornando-se a problemática das superfícies em consola que implicam a opção de suportes adicionais e que não alcançam o mesmo rigor.
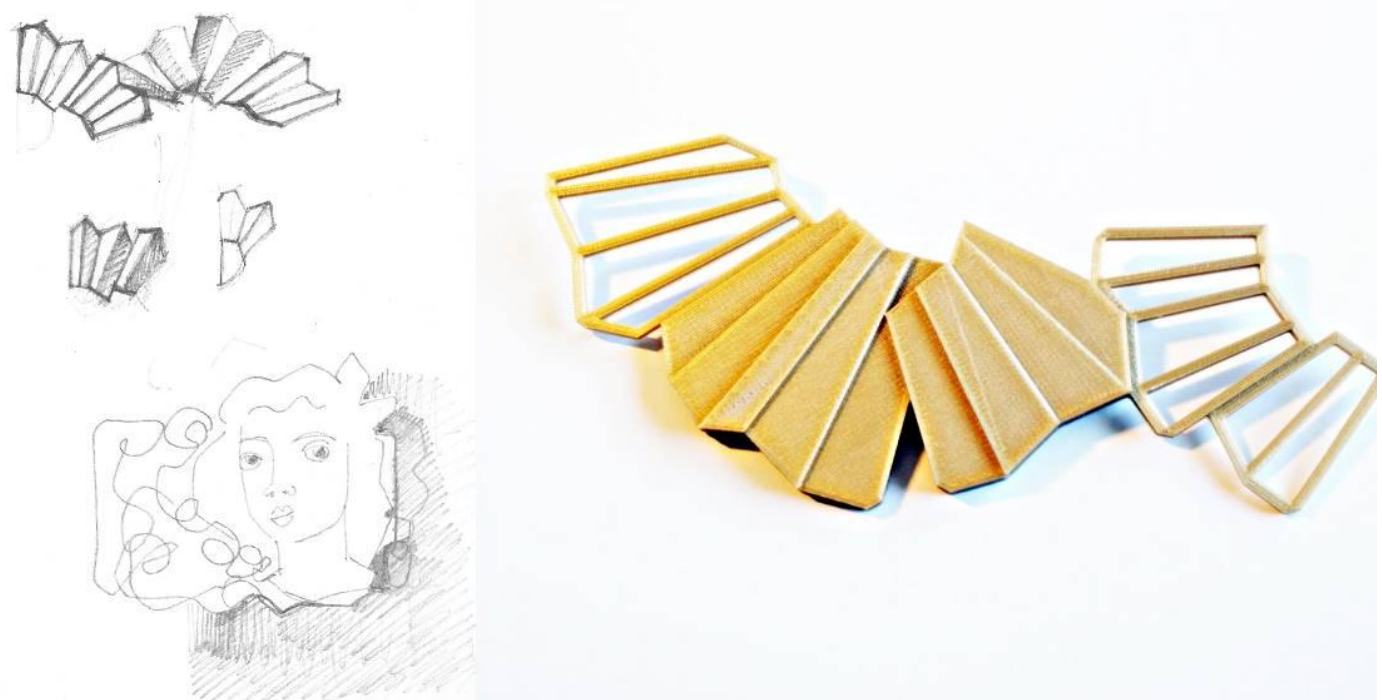

Fig. 3. Esquissos de elementos modulares e protótipo final de pregadeira da colecção As flores de Josefa. 2015. Desenhos e Foto: Mónica Romãozinho.
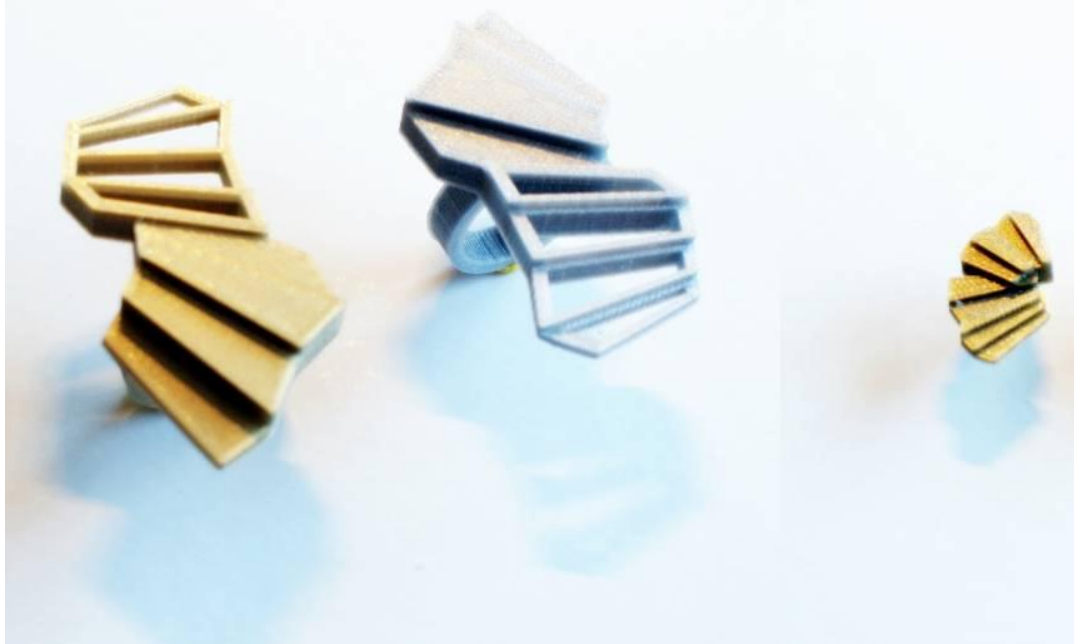

Fig. 4. Protótipos finais de anéis e par de brincos da colecção As flores de Josefa. 2015. Foto: Mónica Romãozinho. 
As pregadeiras e os brincos (Fig.4) inscrevem-se na mesma óptica, mas neste caso, as tramas vazadas deram lugar a malhas opacas e os vazios deram lugar a valores reentrantes correspondentes a valores de sombra. O corpo central das pregadeiras incorporaria a abertura que acolhe o alfinete. Os protótipos intercalares revelaram-se versáteis devido à leveza do material que permite colocá-los em diferentes posições. O jogo de assimetrias contaminaria o desenho dos brincos resultando da subtracção de um dos três elementos modulares, podendo funcionar em todos os ângulos de rotação e permitir alguma versatilidade na sua utilização. O mesmo princípio seria espelhado na colocação propositadamente descentrada do aro do anel.

Ao longo do processo desenvolvemos esquissos juntamente com a modelação tridimensional e impressão 3D em pla (polímero biodegradável designado de poliácido láctico), todas elas metodologias a que recorremos no campo do Design (Fig.5). A prototipagem rápida permitiu avaliar a consistência dos elementos lineares de secção mínima, encaixes e respectivas folgas, níveis de densidade, tempos de impressão total, e qualidade assim como o nível de contraste e tensão entre cheio-vazio e entre planos saliente e reentrantes.
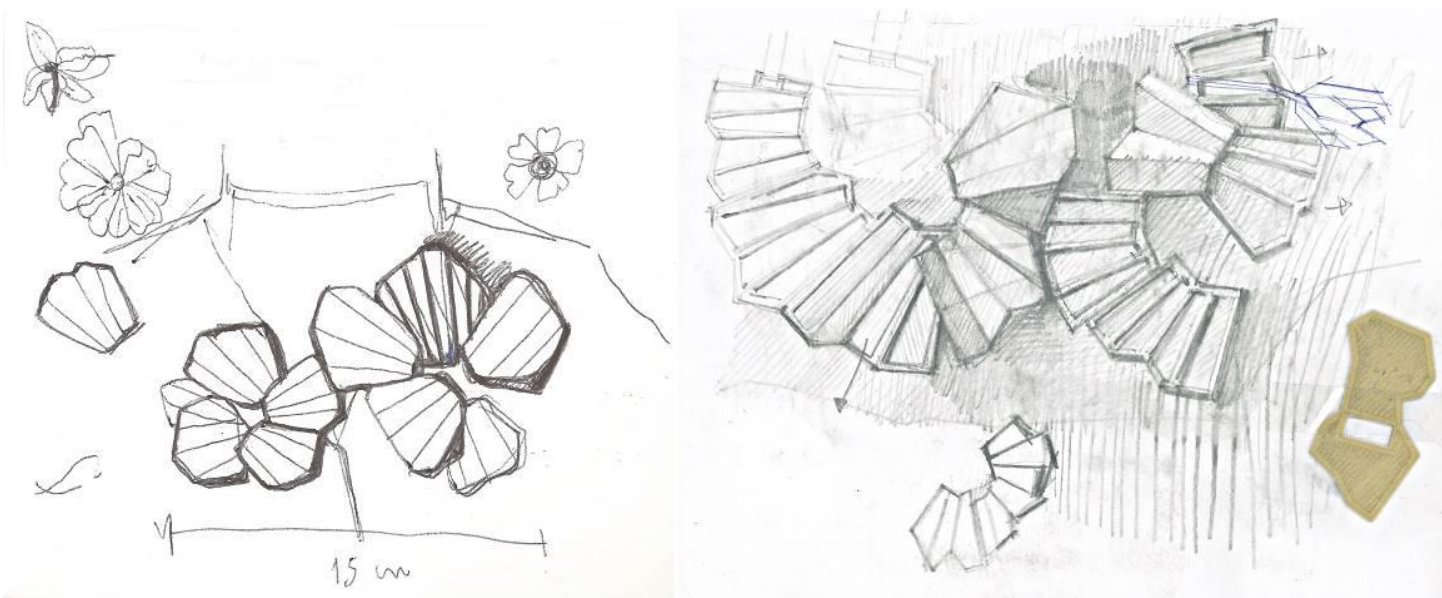

Fig. 5. Esquissos experimentais e desenhos mais avançados da colecção As flores de Josefa. 2015. Desenhos: Mónica Romãozinho.

Se o broche ou pregadeira tem um passado sobretudo de protagonismo na civilização grega permitindo prender as vestes drapeadas, no período barroco evidenciam-se, do mesmo modo, os acessórios para o cabelo. No universo feminino, alheio à moda das perucas, destacou-se a invenção da fontange, um adereço característico da década de $1690^{31}$. O nome terá sido dado em homenagem à marquesa de Fontange, uma das amantes de Luís XIV que, ao verse despenteada durante uma caçada, terá improvisado prendendo os seus cabelos com uma liga. A moda propagou-se e as damas da corte passaram a envolver os cabelos com uma fita com o laço para a frente ${ }^{32}$ acabando por derivar em soluções de toucado mais complexas e menos ergonómicas.

A última peça da colecção parte da intenção de dar continuidade à tradição deste tipo de acessório contemporâneo da pintura de Josefa de Óbidos (Fig.6) ${ }^{33}$. 
Mantém-se presenta a ideia de armação, de estrutura, mas assumida como elemento plástico autónomo e destituída do tecido (gazes, sedas, entre outros) que encobria a mesma no passado. Por outro lado, afastámo-nos de novo de qualquer noção de simetria ao nível do desenho, afirmando de novo a sua contemporaneidade e permitindo a sua colocação em posição a definir, o que implicou equacionar um sistema de fixação ao cabelo igualmente versátil e de uso intuitivo. Há um lado de jogo no modo como podemos manipular estas peças experimentando novos ângulos, à semelhança da pregadeira e dos brincos. Foram adossadas à estrutura pequenas argolas, nas quais podemos encaixar ganchos metálicos tradicionais na cor do cabelo, anulando-se a sua leitura visual. A componente ergonómica determinou a estrutura linear que foi moldada à semelhança do colar.

Optámos por uma paleta de cores presente na obra de Josefa de Óbidos como o branco e o azul, cores presentes na azulejaria daquele período, disseminada pelos holandeses e tão influenciada pelas cerâmicas Ming oriundas da China, assim como o dourado embora mais próximo ao tom do bronze em acabamento mate, presente também em pormenores decorativos da sua pintura e no mobiliário da época em detalhes como o latão (pregaria e embutidos) pois a talha será sobretudo difundida em Portugal no século XVIII. Recorremos ainda ao prateado, cor empregue por Josefa na representação de gomis, taças, entre outros recipientes, sempre embebidos em contrastes acentuados de claro-escuro.

No decurso do projecto, destacamos sobretudo a intenção de trabalhar elementos naturais como se movessem no espaço, tal como acontece nos quadros da pintora, aprofundando-se uma vertente mais escultórica, mais cénica e espacial das peças. No fundo, a joalharia e a arquitectura ou o Design de Interiores podem partilhar princípios como: dialéctica interior-exterior, jogo de escalas, contraste cromático, texturas, oposição luz-sombra, movimento, ritmo, repetição presente nas formas modulares, versatilidade, entre outros. Para Sabine Pagan, enquanto o corpo humano diferencia uma prática da outra, ao mesmo tempo parece aproximá-la, pois o corpo não se reporta apenas a uma entidade física mas também corresponde a uma estrutura mental e quer a arquitectura quer a joalharia contribuem para qualidades humanas como as emoções e a nossa capacidade de memória:

"On closer observation, whilst the human body differentiates one practice from the other, it also appears to bring them closer together, for the body does not only reference a physical entity but also relates to the frame of mind. Together architecture and jewellery contribute to the 'Self' and its human characteristics such as emotions and our capacity for memory" 34 . 


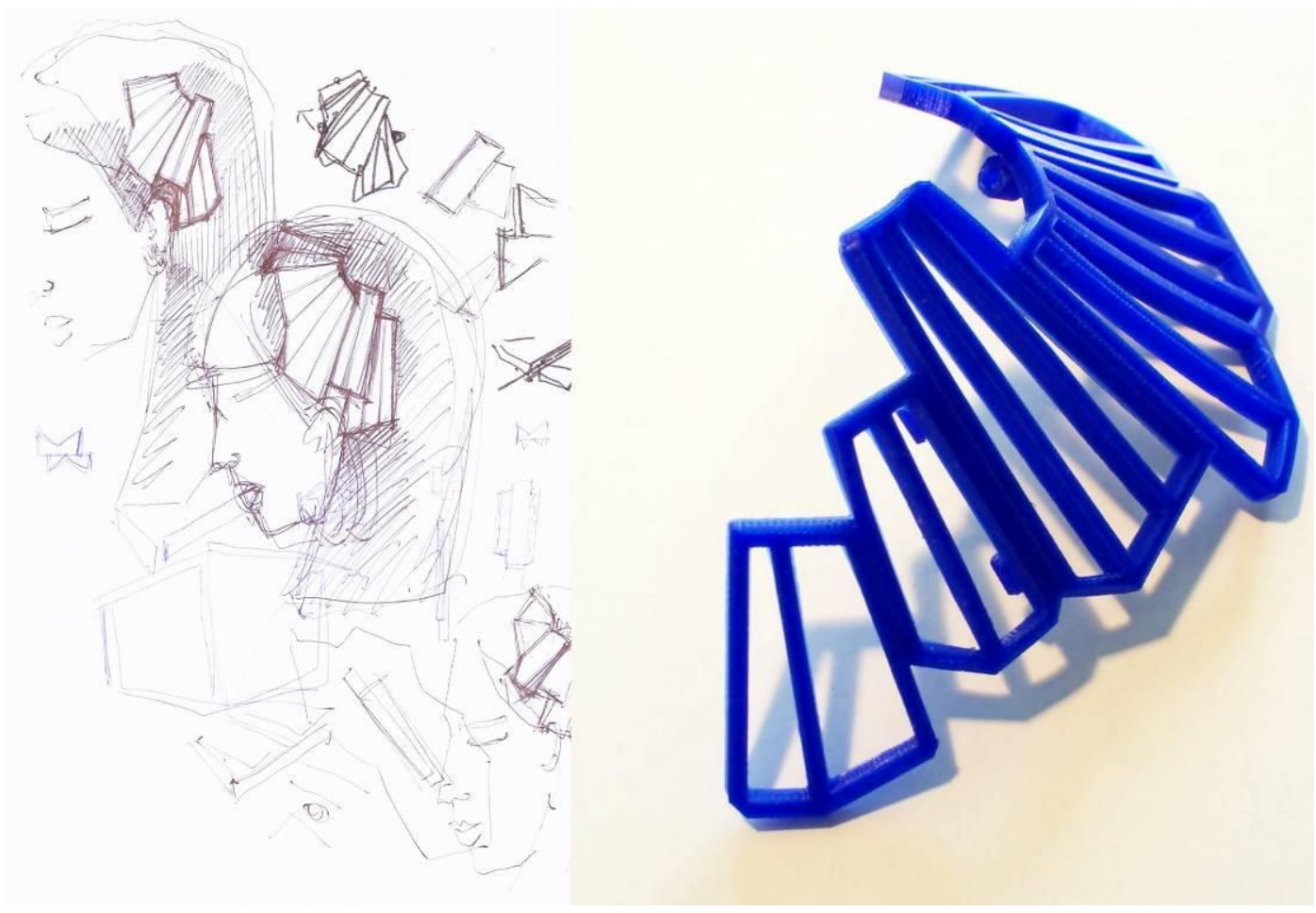

Fig. 6. Desenhos de estudo da colocação do toucado, assim como protótipo final do toucado da colecção As flores de Josefa. 2015. Desenhos e Foto: Mónica Romãozinho.

\section{Síntese conclusiva}

A pintura barroca, neste caso o género da natureza-morta contém uma mensagem moralística, simbolizando o sagrado, o divino, mas espelha simultaneamente uma expressão pessoal do pintor que capta um mundo entendido como universo instável. Procurámos explorar e reinventar alguns dos seus princípios, sobretudo a espacialidade, no âmbito da concepção de peças pensadas como miméticas obras de arte a produzir em séries limitadas. Numa perspectiva internacional e actual, a joalharia de autor contempla objectos únicos, "irrepetíveis", mesmo que produzidos em série, e essa sua identidade não deriva necessariamente do valor do material explorado, mas do seu desenho singular e da sua técnica. Objectos como estes revestem-se de um peso sobretudo simbólico, no sentido em que o corpo funciona como plataforma de comunicação de atributos de acordo com os contextos social, cultural e histórico ${ }^{35}$, contribuindo para a afirmação da identidade do utilizador. É certo que o Design funciona como dispositivo de cruzamento de memórias e experiências do próprio designer, mas queremos acreditar que uma linha como a que apresentámos, de carácter mais abstracto e distante de transposições explícitas, seja um convite para o público conhecer ou revisitar a obra de Josefa de Óbidos. Em qualquer das hipóteses, o objecto ultrapassará o designer, tal como acontece na pintura, até mesmo na pintura do Barroco, premeditada enquanto comunicação de valores mas também resultado da expressão pessoal dos seus artistas e do seu modo de ver o quotidiano e o mundo. 


\section{NOTAS}

${ }^{1}$ CANELAS, Lucinda; BOURGARD, Joana, "O Museu de Arte Antiga tem mais um Menino Jesus feminino e encantador de Josefa de Óbidos”, Público, 22 Janeiro 2014. (acesso 10 Outubro 2016). Disponível em: https://www.publico.pt/culturaipsilon/noticia/o-museu-de-arte-antiga-tem-mais-um-menino-jesus-feminino-eencantador-de-josefa-de-obidos-1620704.

2 MARGOLIN, Victor, "Design in History”, Design Issues, Vol.25, n 2, 30 Março 2009, p. 100.

${ }^{3}$ WALKER, John A., Design History and the History of Design, London, Pluto Press, 1989, p. 75.

${ }^{4}$ MARGOLIN, Victor, "Design in History”, Design Issues, Vol.25, no 2, 30 Março 2009, p. 94.

${ }^{5}$ Ibídem, p. 95.

${ }^{6}$ PEREIRA, José Fernandes, "O barroco do século XVII: transição e mudança”, in História da Arte Portuguesa, Barcelona, Círculo dos Leitores, 1995, p. 16.

${ }^{7}$ Ibídem, p.16.

${ }^{8}$ Ibídem.

${ }^{9}$ Portuguese Furniture: Collection guide, Lisboa, Museu Nacional de Arte Antiga, 2000, p. 26.

${ }^{10}$ PEREIRA, Ana Marques, Mesa Real: Dinastia de Bragança, Lisboa, A Esfera dos Livros, 2012, pp. 86-87.

11 PEREIRA, José Fernandes, "O barroco do século XVII: transição e mudança", in História da Arte Portuguesa, Barcelona, Círculo dos Leitores, 1995, p. 24.

12 Ibídem, p. 24.

${ }^{13}$ MARAVALL, Jose Antonio, La cultura del Barroco, Barcelona, Ariel, 2007, p. 507.

${ }^{14}$ Ibídem.

15 PEREIRA, José Fernandes, "O barroco do século XVII: transição e mudança", in História da Arte Portuguesa, Barcelona, Círculo dos Leitores, 1995, p. 14.

${ }^{16}$ MARAVALL, Jose Antonio, La cultura del Barroco, Barcelona, Ariel, 2007, p. 505.

17 AZAMBUJA, Sónia, A linguagem simbólica da natureza: A flora e a fauna na pintura seiscentista portuguesa, Lisboa, Nova Veja, 2009, p. 39.

${ }^{18}$ Ibídem.

${ }^{19}$ Ibídem, p. 41.

${ }^{20}$ Ibídem.

${ }^{21}$ Ibídem, p. 42.

${ }^{22}$ Ibídem, p. 32.

23 “A árvore e os seus frutos (Mt7, 16-20; 12, 33-37)", in O Evangelho segundo São Lucas, Torres Novas, Difusora Bíblica, 2016.

24 AZAMBUJA, Sónia, A linguagem simbólica da natureza: A flora e a fauna na pintura seiscentista portuguesa, Lisboa, Nova Veja, 2009, pp. 42-45.

${ }^{25}$ SERLIO, Sebastiano, Tercero y Cuarto Libro de Architectura, Trad. por Francisco de Villalpando, Toledo, Casa de Iván de Ayala, 1552, p. 73.

${ }^{26}$ Ibídem, p. 518.

${ }^{27}$ Ibídem, pp. 518-519.

${ }^{28}$ PEZZOLO, Dinah Bueno, Por dentro da moda: definições e experiências, São Paulo, editora Senac, 2009, p. 34.

${ }^{29}$ MARAVALL, José Antonio, La cultura del Barroco, Barcelona, Ariel, 2007, p.517.

30 MUNARI, B., 1966, A arte como ofício, 2nd ed., Trad. por W. Ramos, 1982, Lisboa, Editorial Presença/Martins Fontes, p. 130.

${ }^{31}$ LAVER, James, A roupa e a moda: uma história concisa, Trad. por Christina Probert, $4^{\mathrm{a}}$ reimpressão, São Paulo, Companhia das letras, 1999, p. 122.

${ }^{32}$ Ibídem.

${ }^{33}$ A colecção engloba mais peças para além das apresentadas no artigo. 
${ }^{34}$ PAGAN, S., "Contemporary Jewellery: A Phenomenological approach to making informed by Architecture", in: ACUADS CONFERENCE, 2011: creativity: brain - mind - body: A view into the future of Australian Art and Design Schools, (21 - 23 September 2011), p.1. (acesso 2 Novembro 2012). http://acuads.com.au/conference/article/contemporary-jewellery-a-phenomenological-approach-to-makinginformed-by-architecture/. (Accessed 2 November 2015).

${ }^{35}$ Ibídem.

Fecha de recepción: 14 de octubre de 2016

Fecha de revisión:15 de noviembre de 2016

Fecha de aceptación: 21 de noviembre de 2016 